\title{
Les francophones, la francophonie et Onésime Reclus
}

\section{Brigitte Murray}

C'est à Onésime Reclus, géographe français, que nous devons les concepts et les mots francophone et francophonie. Il les a écrits et définis la première fois dans son ouvrage intitulé France, Algérie et colonies (Deniau, 1983; Diouf, 2008; Maltais, 2008; Provenzano, 2006-2007; Reclus, 1883). Déjà, à cette époque coloniale, la définition que proposait Onésime Reclus pour le terme francophone revêtait un caractère inclusif, le mot francophone se définissant par « tous ceux qui sont ou qui semblent destinés à rester ou à devenir participants de notre langue » (Reclus, p. 422).

Qui est Onésime Reclus, ce géographe français issu d'une famille protestante, dont le père était pasteur et dont la mère a mis au monde 14 enfants? (Reclus, 1917) Ce bref portrait permettra d'en savoir un peu plus à son sujet.

\section{Quand les voyages forment la jeunesse}

Onésime Reclus est né le 22 septembre 1837 à Orthez, en France, et il est décédé le 30 juin 1916, à Sainte-Foy-la-Grande, en France. Il a fait des études de droit à la Sorbonne. Toutefois, au grand dam de sa mère, madame Zéline Trigant, il ne deviendra pas professeur d'université comme l'est devenu son frère Élisée Reclus, qui a acquis une grande renommée en tant que géographe. Il entreprendra plutôt son service militaire à Kolea, en Afrique. C'est d'ailleurs son séjour en Afrique qui influencera grandement le géographe qu'il est devenu (Reclus, 1917).

Une fois libéré du service militaire - parce qu'il avait bien du mal à y souffrir la discipline qui y régnait -, Onésime Reclus se rendra à Alger pour y occuper différents métiers, comme précepteur et garçon de café (Reclus, 1917). Quelque temps plus tard, il rentrera en France, où il sera embauché par la maison d'édition Hachette, établie à Paris. Il 
y occupera le poste de rédacteur des guides de voyage Joanne. Ce travail l'amènera à scruter de fond en comble la France à pied. Ainsi connaitra-t-il tous les recoins de la France. En plus d'avoir rédigé des guides de voyages Joanne, Onésime Reclus a écrit des ouvrages, dont les suivants :

1870 Dictionnaire des Communes de la Suisse (publié sous le nom de plume Louis Couturier)

1877 La Terre à vol d'oiseau

1880 France, Algérie et colonies

1889 Nos Colonies

1889 Le plus beau royaume sous le ciel

1904 Lâchons l'Asie, prenons l'Afrique : où renaître? et comment durer?

1906 La France à vol d'oiseau

1906 Le partage du monde

1909 Le Manuel de l'eau

1914 Grande géographie illustrée

1917 Un grand destin commence (publié à titre posthume)

Alors qu'il travaille pour la maison d'édition Hachette et qu'il rédige des ouvrages, Onésime Reclus fonde une famille. Il se marie en 1872 et quitte Paris en 1873 pour aller vivre à Chaintréauville, où il y vivra pendant 14 ans, jusqu'en 1886. C'est là qu'il y verra grandir ses six enfants. En 1886, il ira s'établir à Sainte-Foy-la-Grande pour tenir compagnie à sa mère, qui était alors veuve (Reclus, 1917).

\section{La doctrine d'Onésime Reclus}

La doctrine d'Onésime Reclus, c'est l'influence du milieu. Selon lui, l'humain est moins la résultante de ses ancêtres qu'il n'est le produit de son environnement, qu'il s'agisse de la montagne ou de la plaine, de la forêt ou du désert. Par ailleurs, il ne croit pas aux races (Reclus, 1917). Cette doctrine s'inscrit dans deux réalités présentes encore aujourd'hui : celle du métissage et celle de l'immigration. 
D’abord, Onésime Reclus reconnait que le peuple français est métissé. Dans son ouvrage (1899) intitulé Le plus beau royaume sous le ciel, il écrit :

Nés de mélanges infinis, dix fois plus croisés qu'ils ne l'imaginent, ayant des ancêtres blancs, noirs, jaunes, les Français ne se ressemblent guère; il en est peu qui aient le même visage, [la] même taille et [la] même allure. Des familles blondes aux yeux bleus, grandes, élancées, se sont unies en France à des familles petites et trapues, brunes, aux yeux noirs. (p. 753)

Onésime Reclus reconnaît également qu'à cette époque-là, l'immigration était déjà présente en France, à cette époque-là. Dans Le plus beau royaume sous le ciel (1899), il écrit : «Le recensement de 1896 a trouvé parmi nous 1027490 étrangers. » (p. 767)

\section{L'avenir de la francophonie selon Onésime Reclus}

À l'époque d'Onésime Reclus, le français jouit d'une grande visibilité et d'une renommée enviable. En effet, c'est la langue des protocoles, des traités, des conférences, des congrès internationaux, des salons, des théâtres, de la diplomatie (Reclus, 1899, p. 830). Malgré le fait qu'Onésime Reclus souhaitait ardemment que la francophonie puisse survivre et même atteindre des destinées universelles, il doutait que son rêve puisse se réaliser.

À ce sujet, deux raisons expliquent ses doutes : le taux de natalité en France et la vitalité de la langue française. D'abord, pour ce qui est du taux de natalité en France, il ne permettait pas de maintenir un flot d'émigration suffisant pour occuper, mettre en valeur et franciser un empire comparable à celui de l'Angleterre. Ensuite, Onésime Reclus (1899) reconnaissait que l'anglais était en train de passer au premier rang et que derrière l'anglais prenaient de l'expansion le russe (qui s'emparait alors de l'Asie), l'espagnol (qui était présent en Amérique du Sud) et le portugais (qui s'implantait au Brésil) (Reclus, p. 802).

Alors, Onésime Reclus se posa les questions suivantes : Où la francophonie pourrait-elle renaitre? Comment la francophonie pourrait-elle durer? «L'Afrique », de s'exclamer Onésime Reclus.

Il semble que les propos d'Onésime Reclus aient été prophétiques. En effet, l'Organisation internationale de la francophonie (2018a), organisme qui chapeaute tous les 
États, gouvernements et organismes qui s'inscrivent dans la francophonie, écrit ce qui suit dans Le rapport de la langue française dans le monde 2014 :

[...] le français réunit des locuteurs dont le cercle s'élargit, mais dont le centre s'enracine progressivement en Afrique. Ainsi, ce sont désormais les Africains qui décideront de l'avenir de la Francophonie.

Selon l'Organisation internationale de la francophonie (2018b), l'Afrique comptera $85 \%$ des francophones en 2050.

\section{Références}

Deniau, X. (1983). La francophonie. Paris, France : Presses Universitaires de France.

Diouf, A. (2008). Préface. Dans L. Beaudoin et S. Paquin (dir.), Pourquoi la Francophonie? (p. 11-19). Montréal, Québec : VLB Éditeur.

Maltais, B. (2008). Où s'en va la francophonie? Dans L. Beaudoin et S. Paquin (dir.), Pourquoi la Francophonie? Longueuil, Québec : VLB Éditeur.

Organisation internationale de la francophonie (2018a). Qui sommes-nous? Consulté en ligne le 5 février 2018, à la page suivante :

https://www.francophonie.org/Langue-Francaise-2014/projet/Rapport-OIF-2014.pdf

Organisation internationale de la francophonie (2018b). Estimation des francophones.

Consulté en ligne le 5 février 2018, à la page suivante : http://www.francophonie.org/Estimation_des_francophones.html

Provenzano, F. (2006-2007), La «francophonie»: définitions et usages. Dans

N. Quaderni, Le tanatopouvoir : politiques de la mort, 62, 93-102.

Reclus, O. (1883). France, Algérie et colonies. Paris, France : Librairie Hachette.

Reclus, O. (1899). Le plus beau royaume sous le ciel. Paris, France : Librairie Hachette.

Reclus, O. (1917). Un grand destin commence. Paris, France : La Renaissance du livre. 